\title{
Yonca Silaj ve Besleme Kalitesinin FT-NIRS Teknolojisi ile Saptanması
}

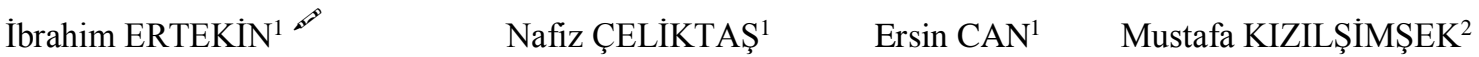 \\ ${ }^{1}$ Mustafa Kemal Üniversitesi Ziraat Fakültesi Tarla Bitkileri Bölümü Antakya/HATAY \\ ${ }^{2}$ Kahramanmaraş Sütçü İmam Üniversitesi Ziraat Fakültesi Tarla Bitkileri Bölümü \\ Onikişubat/KAHRAMANMARAŞ \\ $\triangle$ :ibrahim.ertkn@hotmail.com
}

Geliş (Received): 02.11.2017

Kabul (Accepted): 15.12.2017

\begin{abstract}
ÖZET: Farklı bakteri izolatı uygulamaları neticesinde Lactobacillus bifermentans, yonca otundan en kaliteli silaj oluşumunu teşvik etmiştir. Oluşan silajın kurutulmuş örnekleri NIRFlex N-500 cihazında, 4000-10000 cm-1 dalga aralığında taranarak spektral tanılaması yapılmış ve daha önceden saptanan kimyasal referans değerler NIRCal kemometrik yazılım programında, spektrumlara karşılık olarak kaydedilmiştir. Normalizasyon, dengeleme ve türev ön muamelesi uygulanan spektrumlarda ölçüm hataları azaltılarak silaj kalite parametreleri için kalibrasyonlar optimize edilmiştir. Geliştirilen kalibrasyonların R2 CAL, R2 VAL, SEC, SEV ve VsetBIASS istatistiklerine göre silaj organik asitlerinden laktik asit başta olmak üzere, asetik asit ve propiyonik asit'in yüksek ancak bütirik asit'in daha düşük doğrulukta okunabileceği belirlenmişsir. Farklı silaj parametrelerinin kimyasal değerleri ile NIRS okuması arasındaki ilişkide R2 değerleri bütirik asit, ham yă̆ ve silaj gaz üretim parametreleri dışındaki tüm besleme ve kalite özellikleri için \%70 değerinin üzerinde belirlenmiştir.
\end{abstract}

Anahtar kelimeler: Yonca silaj1, besleme kalitesi, LAB, FT-NIRS.

\section{Silage Quality and Nutritional Features Determination for Alfalfa by FT-NIRS}

\begin{abstract}
As a result of different lactic acid bacterial applications, Lactobacillus bifermentans has promoted the highest quality silage formation from alfalfa. The dried samples of the silage were spectrally scanned at a wavelength of 4000-10000 cm-1 on NIRFlex N-500 instrument. The previously determined chemical reference values were recorded as corresponding to obtained spectrums by using the NIRCal chemometric software. The errors originating from the measurements were reduced by applying normalization, balancing and derivative statistical pretreatments to the spectrums of the parameters, and thus the calibrations were optimized. It has been determined that acetic acid and propionic acid are higher but butyric acid can be predict with lower accuracy according to R2CAL, R2VAL, SEC, SEV and VsetBIASS statistics of the developed calibrations. Relevant regression coefficient between the chemical values of the different silage parameters and their NIRS predictions were determined above $70 \%$ for all feed and quality characteristics except butyric acid, crude oil and silage gas production parameters.

Key words: Alfalfa silage, nutritional quality, LSB, FT-NIRS.
\end{abstract}

\section{GíRiş}

Yonca (Medicago sativa L.) besleme kalitesi nedeniyle dünyada silaj üretimi için yaygın bir şekilde değerlendirilen önemli bir baklagil yem bitkisidir (Kung ve ark., 2003; Coblentz ve ark., 2014). Bununla birlikte türün yüksek tamponlanma kapasitesi, düşük kuru madde ve suda eriyebilir karbonhidrat içeriği silolanmasını zorlaştırıcı karakterleridir (Dewhurst ve ark., 2003). Bitkideki kuru madde oranını arttırmak için soldurarak silolama yaygın bir şekilde kullanılmaktadır. Yonca otundan elde edilen silajın fermentasyon ve yem kalitesinin bilinmesi hayvansal üretimde oldukça önemlidir.

Yakın kızılötesi yansıma spektroskopisi (NIRS) bitki biyokimyasal kompozisyonun belirlenmesinde son yıllarda yoğun olarak kullanılan bir teknik haline gelmiştir (Youngentob ve ark., 2012). NIRS ile yapılan okumalar, farklı yem örneklerindeki kalite farklılıklarını hızlı bir şekilde belirleyebilmek amacıyla 30 yıldan fazla bir süredir kullanılmaktadır. Hayvan besleme açısından hayvansal verimliliğin takibi ve olası değişimlerin nedenlerinin belirlenmesi oldukça önemlidir. Bu açıdan yem kalitesindeki değişimlerin anlık kontrolü ve rasyonun bu değişime göre yeniden şekillendirilmesi yüksek hayvansal verimlilik ve kalite için bir zorunluluktur. NIRS kimyasal analiz yöntemlerine göre sadelik, hı, kimyasal atık oluşturmama ve ürünün fonksiyonelliğini tahmin açısından düşük maliyet gerektirmesi yönleri ile büyük avantajlar sunmaktadır (Lee ve ark., 2011).

Yürütülen bu çalışma kapsamında; yonca silajı kuru örneklerinde fermentasyon ve baz1 yem kalite parametrelerinin, yakın kızılötesi yansıma spektroskopisi ile doğrudan ve hızlı bir şekilde tahmin edilebilme olanakları araştırılmıştır.

\section{MATERYAL ve YÖNTEM}

Bu çalışma Kahramanmaraş Sütçü İmam ve Mustafa Kemal Üniversitelerinin Ziraat Fakültesi Tarla Bitkileri Bölümlerinde 2017 yılında yürütülmüştür. Bazı laktik asit bakteri izolatlarının, yonca bitki materyaline inoküle edilmesiyle yonca silajının fermentasyon profili ve bazı yem kalite özellikleri üzerine etkisi incelenmiştir. Elde edilen sayısal referans veriler üzerinden NIRS kalibrasyonları geliştirilmiştir. 


\section{MATERYAL}

Bakteriyel inokulant kullanarak elde edilen silajlarda, bitki materyali olarak yaygın yonca (Medicago sativa
Lam.) türü kullanılmıştır. İnokulant olarak kullanılan bakteri izolatları ve bazı özellikleri Çizelge 1.'de verilmiştir.

Çizelge 1. Çalışmada kullanılan laktik asit bakterilerine ait bilgiler.

\begin{tabular}{|c|c|c|c|c|c|c|}
\hline $\begin{array}{c}\text { Sira } \\
\text { No }\end{array}$ & İzolat Adı & Tür Adı & Koloni Tipi & $\begin{array}{c}\text { Laktik Ait } \\
\text { Urretimi } \\
(\mathrm{mmol} / \mathrm{L})\end{array}$ & $\begin{array}{c}\text { Laktik } \\
\text { Asit/Toplam } \\
\text { Fermente Ürün } \\
(\%)\end{array}$ & Fizyolojik Karakter \\
\hline 1 & LS-55-2-2 & $\begin{array}{c}\text { Lactobacillus } \\
\text { brevis }\end{array}$ & Bacillus & 70.02 & 81.79 & Heterofermentatif \\
\hline 2 & L-70-6-1 & $\begin{array}{c}\text { Leuconostoc } \\
\text { citerum }\end{array}$ & Coccus & 53.47 & 91.51 & Homofermentatif \\
\hline 3 & LS-65-2-1 & $\begin{array}{c}\text { Lactobacillus } \\
\text { bifermentans }\end{array}$ & Bacillus & 56,65 & 94,66 & Homofermentatif \\
\hline 4 & LS-3-3 & $\begin{array}{c}\text { Lactobacillus } \\
\text { plantarum }\end{array}$ & Bacillus & 54,59 & 90,26 & Homofermentatif \\
\hline 5 & LS-72-2 & $\begin{array}{c}\text { Lactobacillus } \\
\text { plantarum }\end{array}$ & Bacillus & 54,00 & 93,94 & Homofermentatif \\
\hline
\end{tabular}

\section{YÖNTEM}

Yonca\%50 çiçeklenme döneminde (yaklaşık $390 \mathrm{~g}$ $\mathrm{kg}^{-1} \mathrm{KM}$ ) elle biçilmiş ve elde edilen biyokütle $3-5 \mathrm{~cm}$ boyutunda laboratuvar tipi parçalama makinesi ile parçalanarak silolanmıştır. Yonca otu üzerine 5 adet bakteri kültürü ile $5^{*} 10^{5} \mathrm{kob} / \mathrm{g}$ yeşil ot yoğunluğunda laktik asit bakteri inokulasyonu yapılmıştır. Silolama, silaj torbalarının delinmesi ve hava alması gibi olumsuzlukları ortadan kaldırabilmek için her bir uygulamadan 5 tekerrür olacak şekilde $(6 * 5=30)$ gerçekleştirilmiştir ve daha sonra siloların açılması sırasında bu tekerrürlerden hava almamış olan 3 tekerrür kullanılmıştır. Silolama işlemi $3 \mathrm{~L}$ hacmindeki vakum torbalarına $400 \pm 40 \mathrm{~g}$ silaj materyalini içerecek şekilde endüstriyel vakumlu paketleme cihazı ile yapılmıştır. Elde edilen silajlar 75 günlük silolama sürecinden sonra açılmıştır.

\section{1. $p H$ 'nin belirlenmesi}

20 g silaj örneği $180 \mathrm{ml}$ Ringers solüsyonunda el blenderi ile yüksek devirde 90 sn karıştırıldıktan sonra Whattman 54 kağıdı ile süzülmüş ve pH ölçümleri bu süzükte yapılmıştır.

2. Kimyasal analizler

Her silaj uygulamasından yaklaşı $50 \mathrm{~g}( \pm 0.5 \mathrm{~g})$ örnek alınmış, etüvde $78{ }^{\circ} \mathrm{C}$ 'de 48 saat süre ile kurutularak ögütülmüştür $(\leq 0,2 \mathrm{~mm})$. Kuru maddede ADF ve NDF analizleri ANKOM lif analiz cihazından (Fiber Analyzer, ANKOM marka, A220 model) yararlanılarak yapılmıştır (Van Soest ve ark., 1991). Örneklerin azot içeriği kjeldahl metodu ile belirlenmiş ve 6.25 katsayısı ile çarpılarak örnek protein içerikleri hesaplanmıştır (AOAC, 1990). Ögütülmüş örneklerden $200 \mathrm{mg}$ alınarak $30 \mathrm{ml}$ çözeltiyle $(10 \mathrm{ml}$ rumen sıvısı+20 ml yapay tükürük) $100 \mathrm{ml}$ hacimli özel cam şırıngalar (Model Fortuna, Häberle Labortechnik, Lonsee-Ettlenschieß, Germany) içerisinde $39{ }^{\circ} \mathrm{C}$ ' de inkübe edilmiş ve fermentasyon sırasında açığa çıkan gazlar 24. saatte ölçülerek in vitro gaz üretimi saptanmıştır (Ørskov ve McDonald, 1979). Yemin metabolik enerji (ME) ve organik madde sindirimi
(OMS) ise 24 saatlik gaz üretim değerleri üzerinden aşağıdaki formüller yardımı ile hesaplanmıştır (Menke ve ark., 1979).
(1) $\quad \mathrm{ME}(\mathrm{MJ} / \mathrm{Kg} \mathrm{KM})=$

$2.20+0.1357 * \mathrm{GÜ}+0.0057 * \mathrm{HP}+0.0002859 * \mathrm{HY}$

$$
\text { (2) OMS }(\%)=
$$

$14.88+0.8893 * \mathrm{GÜ}+0.0448 * \mathrm{HP}+0.0651 * \mathrm{HK}$

$\mathrm{GÜ}=24$ saatlik fermentasyon sonucu açığa çıkan gaz miktarı (ml)

$\mathrm{HP}=$ Yemin ham protein içeriği $(\mathrm{g} / \mathrm{kg} \mathrm{KM})$

$\mathrm{HY}=$ Yemin ham yağ içeriği $(\mathrm{g} / \mathrm{kg} \mathrm{KM})$

$\mathrm{HK}=$ Yemin ham kül içeriği $(\mathrm{g} / \mathrm{kg} \mathrm{KM})$

Açılan silajlarda organik asit kompozisyonunun (laktik asit (LA), asetik asit (AA), bütirik asit (BA) ve propiyonik asit (PA)) belirlenmesi HPLC ile yapılmıştır (Quiros ve ark., 2009). Hazırlanan örnekler, örnek temizleme prosedüründen sonra HPLC' de $42{ }^{\circ} \mathrm{C}$ 'de 0.6 $\mathrm{ml} / \mathrm{dk}$ akış hızında ve RID dedektör kullanarak tespit edilmiştir.

\section{NIRS kalibrasyonlart}

NIRS kalibrasyonları, FT (Fourier-transform) NIR teknolojisi olan NIRFlex N-500 (BÜCHI Labortechnik $A G$, İsviçre) cihazında yürütülmüştür.

Kurutulup, ögütülmüş 7-10 g silaj örnekleri, ince bir tabaka halinde cam petri kutusu $(100 \times 20 \mathrm{~mm})$ içerisine yayılmıştır. Cihazın okuma haznesine konulan örnekler 4000-10000 $\mathrm{cm}^{-1}$ dalga aralığında taranarak, her bir silajın yakın kızılötesi işınım ile spektral tanılaması yapılmıştır. Spektrumlar, her birisi 32 tarama neticesinde elde edilen 3 tekrarlama ile oluşturulmuştur. . Kalibrasyon işlemi için NIRCal kemometrik yazılım programı kullanılmıştır. Her bir örneğin spektrumlarına karşılık gelen, farklı özelliklere ait referans değerler kaydedilmiş ve spektrumların sayısal tanılaması yapılmıştır. Kemometrik programda, miktar tayini amaçlı nicel NIRS kalibrasyonlarında yaygın olarak kullanılan PLS (Partial Least Squares) regresyon modeli kullanılmış ve böylece referans değerler ile spektrumlar arasında doğrusal bir iliş̧i oluşturulmaya çalışılmıştır. 
Optimizasyon işleminin başlangıcında toplam spektrumların \%66's1 kalibrasyon (Calibration) ve \%33'ü doğrulama (Validation) amaçlı kullanılmıs ancak kalibrasyonu geliştirici ön muameleler sırasında bazı spektrumlar kalibrasyon-validasyon arasinda yer değiştirilmiştir. Bununla birlikte uç değer (outlier) olduğu değerlendirilen bazı örneklere ait spektrumlar silinmiş veya kalibrasyon dıșı tutulmuștur. Dolayısıyla başlangıçtaki oranlar optimize edilen kalibrasyon modelinde değişmiștir. Spektrumların orijinalliğini bozmadan, kalitesini arttırmak, ölçüm hatalarını azaltmak ve istenmeyen yan etkileri elimine etmek amacıyla, incelenen her bir özellik için bazı istatistiksel ön muameleler veya kombinasyonları uygulanmıştır. Spektrum ana hat değişimlerini azaltmak için normalizasyon (n01, SNV), ana hat düzeltmeleri amacıyla dengeleme (mo, mf), spektrumların karmaşık bölgelerini azaltmak için düzgünleştirme ( $(\mathrm{sa} 3, \mathrm{sg} 9)$ ve ana hat etkisini azaltmak amaçlı türev (db1, dg1) ön muameleleri kullanılmıștır. Oluşturulan nicel kalibrasyonlarnn performansi; kalibrasyon (CAL) ve doğrulama (VAL) arasındaki korelasyon katsayısı $\mathrm{R}^{2}$ CAL / $R^{2}$ VAL, kalibrasyon (C), doğrulama (V) ve tahminin (P) nın standart hataları (SEC, SECV-SEP) ve eğim çizgisinin açı değeri (BIASS) ile yorumlanmıştır. Ayrıca kalibrasyon doğruluğu, farklı yonca silaj örneklerinin kimyasal analizi ve geliştirilen NIRS aplikasyonu okuma sonuçları arasındaki ilişki ile de test edilmiştir.

\section{BULGULAR ve TARTISMA}

Farklı bakteri izolatı uygulamaları neticesi olgunlaşan silajda, kalite parametreleri dikkate alındığında, Lactobacillus bifermentans bakteri izolatının, diğer uygulamalardan daha etkin oranda laktik asit üretimine yol açtığı ve böylece pH'nın hızla düşmesini sağlayarak daha kaliteli yonca silajı ürettiği saptanmıştır.

Her bir yonca silaj kalite parametresi için farklı istatistiksel ön muamele veya kombinasyonlarını, spektrum kalitesini iyileştirme açısından etkili oldukları görülmüștür (Cizelge 2.). Örnek üzerindeki farklı fiziksel ve kimyasal uygulamalar, örneğin spektral tanılaması sırasındaki operatör ve prosedür uygulama farklılıkları absorbe edilen spektrum bantlarının üst üste çakışması, doğrusal dağılım göstermemesi, hafif dağıllım ve neticesinde karmaşı bant görünümünün ortaya çıkabilmesine neden olmaktadır (Buchi, 2013). Dolayısıla spektrumları farklı istatistiksel ön muameleler ile matematiksel transformasyonları neticesinde iyileștirilmesi beklenen bir durumdur. Yonca silaj1 kalibrasyon ve doğrulama örnek setlerine ait performans göstergesi olan istatistiki sonuçlar Çizelge 2. ve silaj kalitesinin önemli göstergeleri LA ve $\mathrm{pH}$ parametreleri için Şekil 1'de verilmiştir. Kalibrasyon ve doğrulama okumaları arasındaki korelasyon katsayısı $\left(\mathrm{R}^{2}\right)$ değerlerinin 1'e yakınlıkları açısından değerlendirildiğinde silajın $\mathrm{BA}, \mathrm{HP}, \mathrm{NG}$, ve NDF özellikleri dışında kalan diğer tüm parametreler için oluşturulan kalibrasyonların yüksek doğrulukta olduklarını söylemek mümkündür. Ancak bu değerlendirme açısından korelasyon katsayısı tek başına yeterli bir parametre değildir. Kalibrasyon ve doğrulama spektrumlarına ait standart hataların küçüklügü ve birbirlerine yakınlıkları değerlendirildiğinde ise $\mathrm{PA}, \mathrm{pH}$, HP, HY, NG, ME ve OMS parametrelerine ait kalibrasyonların yüksek gerçeklikte sonuç verebileceği görülmektedir. Nitekim Williams (1987), tahminin standart hatasının, parametreye ait referans değerin \%3’ünden fazla olmaması gerektiğini öngörmektedir. $\mathrm{Bu}$ açıdan $\mathrm{pH}$ ve $\mathrm{NG}$ başta olmak üzere diğer bazı özellikler için geliştirdiğimiz değerlerin bu sınırlar içerisinde oldukları görülmektedir. NIRS kalibrasyonlarında, tahmin okumasının, referans değerden ortalama sapmasının göstergesi olan VsetBIASS değeri AA, BA ve HK oranı parametreleri dışındaki tüm özellikler için oldukça yüksek kabul edilirlik sınırlarında gerçekleşmiştir. Ancak elde edilen istatistiksel veriler yardımı ile okuma doğruluğunu ortaya koymak her zaman tek başına yeterli olamamaktadır. $\mathrm{Bu}$ amaçla benzer örneklerin, optimize edilen NIRS kalibrasyonunda okunarak NIRS ve kimyasal değerler arasındaki ilişkinin ortaya konulması gerçekçiliği arttıracaktır. Nitekim Şekil 2'de, NIRS istatistiklerine göre oldukça iyi bir kalibrasyon olarak değerlendirilen $\mathrm{HY}$ ve NG parametrelerine ait kimyasal ve NIRS okuma sonuçları arasındaki regresyon katsayı değerlerinin düşük olduğu, buna karşın SEC ve SEV değerleri nedeni ile düşük performanslı olarak değerlendirilen LA, AA, HK, ADF ve NDF parametreleri için geliştirilen NIRS kalibrasyonu okumasının ise kimyasal sonuçlarla yüksek doğrulukta benzeştiği görülmektedir.

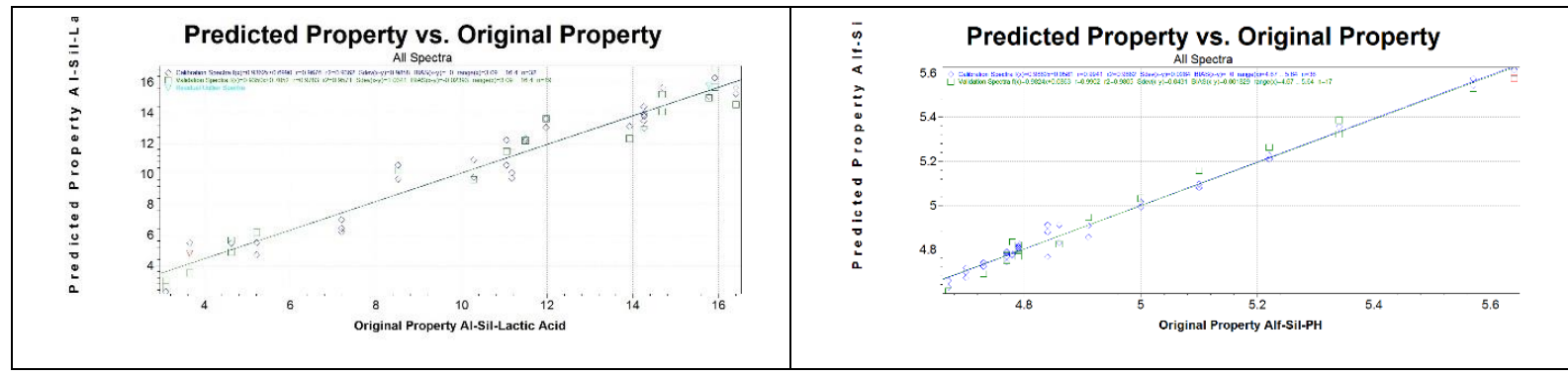

Şekil 1. Yonca silajı LA ve pH değerleri için NIRS kalibrasyonu orijinal ve tahmin değerleri arasındaki ilişki grafikleri. 
Çizelge 1. Farklı yonca silaj kalite parametreleri için oluşturulan NIRS kalibrasyonlarında kullanılan ön muameleler ve kalibrasyon istatistikleri.

\begin{tabular}{|l|c|c|c|c|c|c|}
\hline $\begin{array}{c}\text { Silaj Kalite } \\
\text { Özellikleri }\end{array}$ & $\begin{array}{c}\text { İstatistiksel Ön } \\
\text { Muamele }\end{array}$ & $\mathrm{R}^{2} \mathrm{CAL}$ & $\mathrm{R}^{2} \mathrm{VAL}$ & SEC & SEV & Vset BIASS \\
\hline LA & $\mathrm{db} 1, \mathrm{n} 01, \mathrm{sg} 9$ & 0.9362 & 0.9571 & 0.9858 & 1.0341 & 0.0239 \\
\hline AA & $\mathrm{n} 01, \mathrm{sg} 9, \mathrm{mf}$ & 0.9485 & 0.9394 & 0.8415 & 1.0226 & 0.1257 \\
\hline BA & $\mathrm{dg} 1, \mathrm{sNV}$ & 0.8965 & 0.8990 & 1.4556 & 1.5396 & 0.1404 \\
\hline PA & $\mathrm{dg} 1, \mathrm{sg} 9$ & 0.9223 & 0.9281 & 0.5593 & 0.5606 & 0.0659 \\
\hline pH & $\mathrm{n} 01, \mathrm{mf}, \mathrm{sa} 3$ & 0.9999 & 0.9491 & 0.0028 & 0.0668 & 0.0035 \\
\hline HP & $\mathrm{ds} 2$ & 0.8609 & 0.8944 & 0.5704 & 0.5879 & 0.0496 \\
\hline HY & $\mathrm{ncl}, \mathrm{mf}, \log 9$ & 0.9464 & 0.9742 & 0.6842 & 0.5947 & 0.0508 \\
\hline HK & $\mathrm{db} 1, \mathrm{n} 01, \mathrm{mf}$ & 0.9407 & 0.9422 & 1.2493 & 1.2217 & 0.1062 \\
\hline NG & $\log , \mathrm{dg} 1, \mathrm{sg} 9$ & 0.8808 & 0.8662 & 0.0042 & 0.0044 & 0.0001 \\
\hline ME & $\mathrm{mo}, \mathrm{sg} 9, \mathrm{n} 01$ & 0.9012 & 0.8974 & 0.1128 & 0.1180 & 0.0037 \\
\hline OMS & $\mathrm{mf}, \mathrm{sg} 9, \mathrm{n} 01$ & 0.9181 & 0.8910 & 0.5752 & 0.7971 & 0.0413 \\
\hline ADF & $\mathrm{db} 1, \mathrm{sg} 9$ & 0.9103 & 0.9048 & 0.9897 & 0.9617 & 0.0420 \\
\hline NDF & $\log , \mathrm{mf}$ & 0.7919 & 0.7966 & 1.4582 & 1.4626 & 0.0072 \\
\hline
\end{tabular}
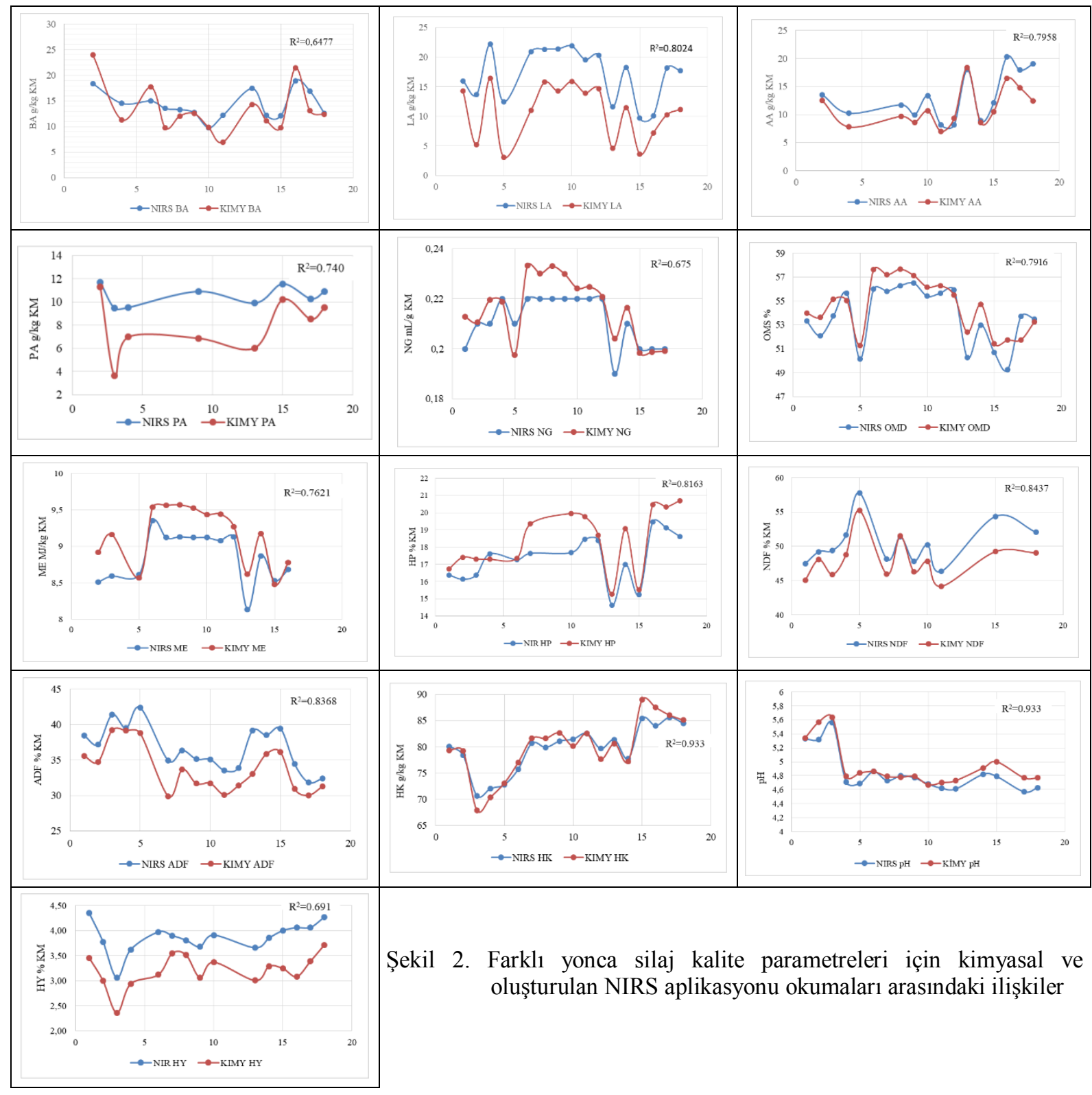

Şekil 2. Farklı yonca silaj kalite parametreleri için kimyasal ve oluşturulan NIRS aplikasyonu okumaları arasındaki ilişkiler 
Farklı silaj parametreleri için geliştirilen kalibrasyon performanslarının Park ve ark. (2005)'nın mısır silajı için oluşturdukları kalibrasyondan çok daha iyi olduğu görülmektedir. Spektrumların toplanması sırasındaki örnek boyutu, örneğin sıkışıklığı, kullanılan cihaz ve kemometrik program, ortam ve örnek sıcaklığ çok parametre bu tarz farklılıkların ortaya çıkmasında etkili faktörlerdir (Shenk and Westerhaus, 1995).

Tüm doğrulama parametreleri açısından irdelendiğinde, silajın ürettiği organik asitler için geliştirilen kalibrasyonların daha da geliştirilmesi gerektiği ortadadır. Park ve ark. (2005) yaş, firında kurutularak ve sivi azot muamelesi sonrasinda ögütülmüş silaj örneklerinin NIRS kalibrasyonlarında farklılıklar oluştuğunu, kurutma sıcaklığından kaynaklı olarak, silajın uçucu yağ bileşenlerinde kayıplar olabileceğini ve bununda kalibrasyonun standart hatasını arttıracağını bildirmişlerdir. Araştırmamızda silaj örnekleri firında kurutularak spektrumları alınmıştır. Dolayısıyla organik asitler açısından NIRS doğruluğun azalması olağan bir sonuçtur.

\section{SONUC}

Yonca silajının fermantasyon ve besleme kalitesinin anlık ve hızlı bir şekilde belirlenmesinde, NIRS yüksek doğrulukta sonuçlar ortaya koyma potansiyeline sahiptir. Nitekim geliştirilen "Yonca Silaj1 NIRS Kalibrasyon Paketi" ile her birisi uzun uğraşı ile saptanabilen 13 farklı kalite parametresinin tamamı 30 sn. içerisinde okunabilir hale getirilmiştir. Ancak en doğru sonuçların alınabilmesi açısından spektrumları depolanan örneklerin, çok farklı koşulları temsil etmesi ve daha çok sayıda örnekle çalışılması gerektiği sonucuna varılmıştır.

\section{KAYNAKLAR}

Association of Official Analytical Chemists (AOAC) 1990. Official Method of Analysis. 15 ${ }^{\text {th }}$ ed., Washington, DC. USA. Pages 66-88.

Buchi 2013. NirCal Operation Manual. BÜCHI Labortechnik AG, İsviçre.

Coblentz WK, Muck RE, Borchardt MA, Spencer SK, Jokela WE, Bertram MG, Coffey KP 2014. Effects of dairy slurry on silage fermentation characteristics and nutritive value of alfalfa. J. Dairy Sci. 97():7197-7211.

Dewhurst RJ, Fisher WJ, Tweed JKS, Wilkins RJ 2003. Comparison of grass and legume silages for milk production. Production responses with different levels of concentrate. J. Dairy Sci. 86(-):2598-2611.
Kung LJr, Taylor CC, Lynch MP, Neylon JM 2003. The effect of treating alfalfa with Lactobacillus buchneri 40788 on silage fermentation, aerobic stability, and nutritive value for lactating dairy cows. J. Dairy Sci. 86(-):336-343.

Lee EJ, Shannon JG, Choung MG 2011. Application of nondestructive measurement to improve soybean quality by near infrared reflectance spectroscopy. In: $\mathrm{Ng} \mathrm{T}-\mathrm{B}$, editör. Soybean Applications and Technology. InTech, pp. 287-304.

Menke KH, Raab L, Salewski A, Steingass H, Fritz D, Scneider W 1979. The Estimation of the Digestibilty and Metabolizable Energy Content of Ruminant Feedstuffs from the Gas Production When They are Incubated with Rumen Liguor. J Agri Sci, 93(-):217222.

Ørskov ER, McDonald P 1979. The Estimation of Protein Degradability in the Rumen from Incubation Measurements Weighted According to Rate of Passsage. J Agric Sci, 28(-):499-503.

Park HS, Lee JK, Fike JH, Kim DA, Ko MS, Ha JK 2005. Effect of Sample Preparation on Prediction of Fermentation Quality of Maize Silages by Near Infrared Reflectance Spectroscopy. Asian-Aust. J. Anim. Sci. 18(5):643-648.

Quiros ARB, Yusty MAL, Hernandez JL 2009. HPLC Analysis of organic Acids Using a Novel Stationary Phase. Talanta, 78(-):643-646.

Shenk JS, Westerhaus MO 1995. The application of near infrared reflectance spectroscopy (NIRS) to forage analysis. In (Ed. G. C. Fahey, Jr.) Forage Quality, Evaluation, and Utilization. ASA, Madison. WI. pp. 406-449.

Van Soest PJ, Robertson JB, Lewis B A 1991. Methods for Dietary Fiber, Neutral Detergent Fiber and Nonstarch Polysaccharides in Relation to Animal Nutrition. Journal of Dairy Science, 74(-):35833597.

Williams PC 1987. Variables affecting near-infrared reflectance spectroscopic analysis. In (Ed. P. Williams and K. Norris) Near-Infrared Technology in the Agricultural and Food Industries. St. Paul, MN: American Association of Cereal Chemists Inc. pp. 143-167.

Youngentob KN, Renzullo LJ, Held AA, Jia XP, Lindenmayer DB, Foley WJ 2012. Using imaging spectroscopy to estimate integrated measures of foliage nutritional quality. Methods Ecol. Evol. 3():416-426. 